\title{
A robótica livre no auxílio da aprendizagem do movimento retilíneo
}

\author{
Marco A. S. Trentin ${ }^{1}$, Carlos Ariel Samudio Pérez², Adriano Canabarro Teixeira ${ }^{1}$ \\ ${ }^{1}$ Curso de Ciência da Computação \\ ${ }^{2}$ Curso de Física \\ Instituto de Ciências Exatas e Geociências - Universidade de Passo Fundo (UPF) \\ BR 285, São José, CEP: 99052-900 - Passo Fundo - RS - Brazil \\ \{trentin, samudio, teixeira\} eupf.br
}

\begin{abstract}
This paper describes a low cost implementation of an alternative to teaching Rectilinear Movement, in physics, composed by hardware and software. This artifact is composed of an inclined ramp with rails, where a trolley moves, and in its chassis is attached an Arduino board, a sensor and a transmitter. Free software and free solutions are used, as well discard materials. This resource enables the realization of real experiences of displacement, as well the captured data visualization along the path, in real time, displayed on a computer screen, assisting the students to understanding the details involved in the displacement.
\end{abstract}

Resumo. Este trabalho focaliza a implementação de uma alternativa de baixo custo para o ensino do Movimento Retilíneo, na área de Física, constituída de hardware e software. Este artefato é composto de uma rampa inclinada com trilhos, onde um carrinho se desloca, em cujo chassi está acoplado uma placa Arduino, sensor e transmissor. São utilizados softwares e soluções livres, além de materiais de descarte. Este recurso possibilita a realização de experiências reais de deslocamento e a visualização de dados capturados ao longo do trajeto, em tempo real, exibidos em uma tela de computador, auxiliando na compreensão pelos alunos dos detalhes envolvidos no deslocamento.

\section{Introdução}

Dentre as principais preocupações dos educadores comprometidos com a melhoria da educação e com a transformação da sociedade, encontra-se a busca permanente pela (re)significação dos conteúdos escolares. A importância de alinhar o ensino com as novas exigências da sociedade contemporânea revela-se na medida em que a tecnologia passa a ocupar destaque na vida das pessoas e permanece distanciada da sala de aula, ao menos em processos diferenciados de apropriação do conhecimento que vão além de utilizá-la como uma extensão da biblioteca ou como espaço de jogos educacionais. É evidente que existem experiências pontuais de utilização excepcional e criativa da tecnologia, mas também é claro que os recursos tecnológicos são subutilizados em nossas escolas, em especial nas escolas públicas que ainda vivenciam um processo de informatização e conexão deficitário. A sociedade contemporânea é mediada pelas tecnologias sendo importante que o sistema educacional a considere como aspecto integrante de sua estrutura pedagógica. No contexto deste texto, entende-se como 
tecnologia todo e qualquer aparato não biológico utilizado para perceber determinado contexto ou conteúdo, bem como os métodos e processos criados para tal compreensão.

No contexto da informática educativa geralmente se associa ao termo "tecnologia" os computadores pessoais que na maioria das vezes estão localizados em um espaço específico da escola, os laboratórios de informática, e embora sejam espaços importantes, não tem propiciado a vivência de processos interdisciplinares, ficando geralmente relegados a uma utilização muito mais limitada do que a realizada pelos alunos fora do ambiente escolar. Seguramente não se trata somente de uma falta de formação adequada para os professores, mas também de questões ligadas a uma infraestrutura técnica que não dá conta das demandas de processamento e conexão, a uma organização curricular que enquadra a tecnologia como mais uma disciplina a ser realizada e, por fim, a uma subutilização da tecnologia, consequência das primeiras questões levantadas.

Neste sentido, detecta-se a necessidade de criar alternativas tecnológicas para processos de aprendizagem no contexto escolar, o que leva a novas reflexões acerca de seus objetivos pedagógicos, uma vez que ela exige um desenvolvimento cognitivo mais complexo. E, uma vez criadas, seria interessante identificar os desdobramentos, potencial e limitações de tais alternativas. Neste contexto, atividades didáticas baseadas em seguir modelos ou memorizar passos devem abrir espaço para processos efetivos de construção de conhecimento, para a compreensão das etapas necessárias para esta construção e para o reconhecimento de quais mecanismos foram ativados durante o processo. Isso representa a superação da pedagogia tradicional muitas vezes presente na ação pedagógica do professor, em especial quando da utilização de recursos tecnológicos, apontando na direção da concepção construtivista, cuja tônica está na interação entre os sujeitos e entre eles e o objeto do conhecimento. Neste contexto de emergência da tecnologia na escola, apresenta-se a robótica como dispositivo potencializador da aprendizagem sendo considerada uma das dez áreas mais importantes de pesquisa no mundo, ainda pouco difundida no Brasil, principalmente em termos educacionais.

Em um contexto maior, atividades educacionais relacionadas à robótica estão se tornando cada vez mais frequentes. Em países de primeiro mundo, em muitas escolas são realizadas atividades relacionadas à robótica ao longo de todas as etapas escolares, desde as séries iniciais (Barbero 2013). Quando alunos se envolvem em atividades relacionadas à robótica, é possível obter uma série de benefícios, a saber: interdisciplinaridade, responsabilidade, criatividade, imaginação, espírito observador, habilidade na resolução de problemas, socialização, comunicação, compreensão visual de matemática e ciências, aprimoramento do raciocínio lógico e abstrato, dentre tantas outras (Malec 2013), (César 2013).

\section{Robótica Educacional Livre como Alternativa Didática}

Há alguns anos, a robótica apresenta grande potencial como ferramenta interdisciplinar. A busca por soluções estimula o espírito investigativo, fortemente motivado pela curiosidade, e permite que o aluno extrapole os conhecimentos individuais de cada disciplina. Assim a robótica assume o papel de uma ponte de ligação interdisciplinar visando a construção do conhecimento coletivo através da aplicação com a realidade. Nesse contexto, a Robótica Educacional ganha força por se tratar da aplicação da 
robótica na área pedagógica, com o objetivo de disponibilizar aos alunos a oportunidade de criar soluções voltadas ao mundo real, de forma a possibilitar o aprendizado de forma dinâmica e estimulante (Santos 2013), (Sergeyev 2012).

Outra característica da robótica é o fato de suas atividades serem mais produtivas quando realizadas por um grupo de pessoas trabalhando em conjunto, e não por um único indivíduo. Congregando a teoria à prática ela é capaz de desenvolver nos alunos alguns conceitos que as demais disciplinas quase não abordam, como: trabalho em equipe, auto-desenvolvimento, capacidade de solucionar problemas, senso crítico, integração de disciplinas, exposição e defesa de pensamentos, criatividade, autonomia e responsabilidade, postura empreendedora, entre outras. Por tratar-se de uma área multidisciplinar, a robótica estimula os alunos a buscarem soluções que integram conceitos e aplicações de outras disciplinas envolvidas, como matemática, física, mecânica, eletrônica, design e informática (Lieberknecht 2013).

Percebe-se, nos últimos anos, que existe um movimento no Brasil por parte do governo federal e também de governos estaduais, para o uso de soluções livres na área de Tecnologia da Informação - TI. Um exemplo disso são os computadores destinados às escolas públicas, que possuem como Sistema Operacional uma distribuição Linux ou o Linux Educacional. E na robótica isso não é diferente; atualmente é possível a criação de projetos de robótica com tecnologias de baixo custo ou mesmo com peças oriundas de descarte de equipamentos eletrônicos. De imediato pode-se concluir que essa área, até então presente apenas em escolas particulares que possuem condições de aquisição de kits de robótica de custos elevados, deixa de estar distante para a realidade da escola pública.

A inserção de recursos tecnológicos no processo de ensino aprendizagem é um grande desafio para o Brasil, pois uma parte da população não tem acesso a recursos computacionais e/ou tecnológicos, sejam esses na escola ou no domicílio. Os kits de robótica proprietários possuem um custo elevado para a realidade brasileira. Além disso, estes kits não possuem muita adaptabilidade no que diz respeito à interação com outros dispositivos que não pertençam ao fabricante ou escolhas de outras linguagens de programação não presentes no kit. Isso engessa a aplicabilidade do kit em diferentes turmas e cria uma dependência tecnológica para com um fabricante (Santos 2013). O que se espera com a Robótica Educacional Livre é oportunizar o acesso às escolas projetos de robótica de baixo custo, não dependendo de verbas vultosas e morosas, e assim acredita-se que projetos realizados nas escolas com robótica poderão vir a auxiliar no estímulo e criatividade, e do poder de resolução de problemas dos alunos.

Atualmente, devido ao sucesso do Arduino, por ser uma plataforma de hardware livre, a robótica educacional começou a tomar grande impulso nos últimos anos. Isso não quer dizer que a robótica educacional livre é recente. Já no início deste milênio algumas escolas brasileiras já realizavam atividades de robótica educacional. Nessa época, elas se valiam de equipamentos obsoletos que eram descartados ou inutilizados e deles eram retirados dispositivos eletromecânicos, como motores e sensores, além de outros materiais que poderiam ajudar o educando na montagem de seus projetos, tais como eixos, roldanas, engrenagens, fiações, bornes de ligação, resistores, transistores, reguladores de tensão, dentre outros (César 2013).

Um exemplo do impulso que a robótica educacional está tomando pode ser visto nas ações em que a NASA - Agência Aeroespacial Americana tem promovido, em 
especial através de projetos, desafios e competições para estudantes de diversas idades do Ensino Básico (NASA 2013). Com essas ações, a NASA visa, também, incentivar profissionais para carreiras que interessam a ela.

No Brasil isso não é diferente. Pode ser citado o exemplo da Olimpíada Brasileira de Robótica (OBR), que é uma das olimpíadas científicas brasileiras apoiadas pelo $\mathrm{CNPq}$, que se utiliza da temática da robótica - tradicionalmente de grande aceitação junto aos jovens - para servir com instrumento para a melhoria do ensino fundamental e médio, estimular os alunos para carreiras científico-tecnológicas, identificar jovens talentosos e promover debates e atualizações no processo de ensinoaprendizagem brasileiro. Ela teve sua primeira edição nacional em 2007 e a última edição da OBR contou com 20.000 alunos em todo o território nacional (OBR 2013).

\subsection{O Arduino como uma Plataforma de Hardware Livre para Robótica}

O Arduino (Figura 1) é uma plataforma de prototipagem eletrônica de hardware livre, projetada com um microcontrolador Atmel AVR de placa única, com suporte de entrada/saída embutido, uma linguagem de programação padrão, essencialmente $\mathrm{C} / \mathrm{C}++$. O objetivo do Arduino é o de permitir a criação de robôs e outros dispositivos programáveis com baixo custo, principalmente para aqueles que não teriam alcance a controladores mais sofisticados (e caros) e de ferramentas de programação mais complexas (Arduino 2013).

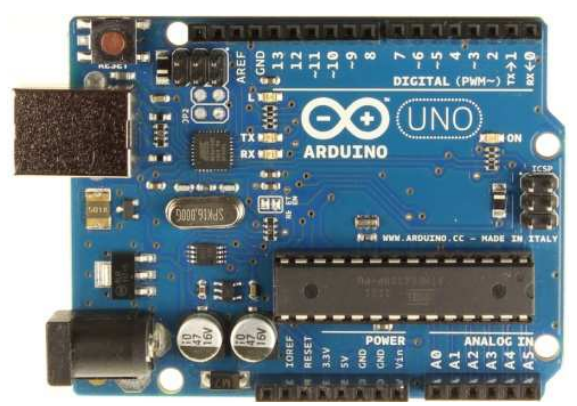

Figura 1. Placa Arduino (ARDUINO, 2013)

Esse grande crescimento nos últimos anos da robótica educacional livre se deve, em grande parte, ao baixo custo da placa Arduino e da facilidade em sua programação. Diante disso, muitos componentes, dispositivos e shields tem sido desenvolvidos para atuarem em conjunto com o Arduino. Como exemplo pode-se citar: dispositivos de saída (dispositivos de áudio e vídeo), dispositivos de entrada (sensores de cor, imagem, temperatura, luminosidade; GPS; botões, encoders), dispositivos de comunicação (wi-fi, ethernet, bluetooth, GSM) entre tantos outros, com um baixo custo de aquisição (César 2013).

\section{Método Utilizado}

Para o experimento em questão, um primeiro protótipo foi construído, composto por (a) uma rampa inclinada de deslocamento, (b) um sarrafo com imãs e (c) um carrinho com sensor magnético. Com esses 3 componentes é possível adquirir dados do deslocamento de um objeto que se move em uma rampa inclinada. Esses dados são repassados, em 
tempo real, a um computador e assim são tratados da forma que melhor convier, conforme as necessidades do professor (ou do aluno). Nas seções a seguir serão descritos cada um desses 3 componentes.

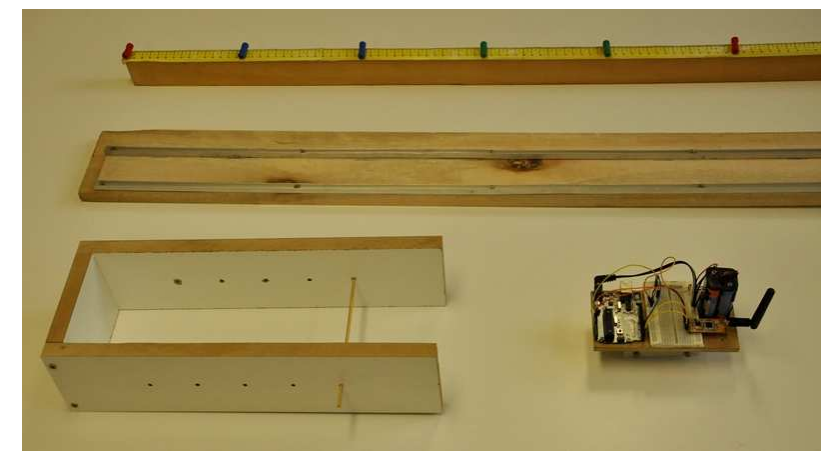

Figura 2. Trena com imãs, rampa e carrinho

\subsection{Rampa Inclinada de Deslocamento}

A rampa utilizada nesse protótipo possui 1,5 metros de comprimento e 20 centímetros de largura. Para tal foi utilizada uma tábua lisa, a fim de diminuir ao máximo o atrito. Nela foram fixados 2 trilhos de alumínio, de mesmo comprimento da tábua, que servem para criar uma guia para que o carrinho possa se deslocar em linha reta, sem sair do rumo. Esses trilhos podem ser substituídos por qualquer outro material (barras de alumínio, ferro, plástico, madeira, etc), desde que sejam retilíneos. Essa rampa é apoiada em um suporte, com diferentes graduações de altura, para que o professor (ou alunos) possa regular a inclinação da rampa para, consequentemente, alterar a aceleração do carrinho em sua descida.

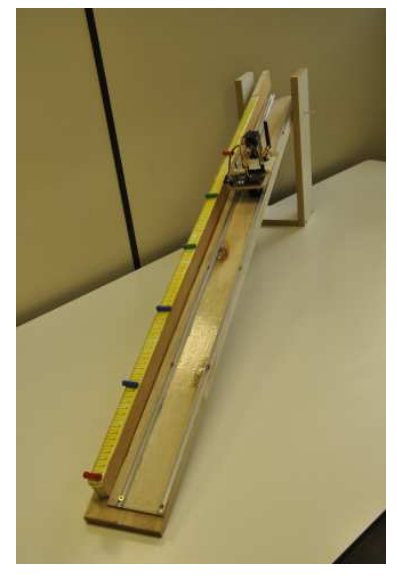

Figura 3. Carrinho em deslocamento na rampa

\subsection{Sarrafo com Imãs}

Foi utilizado um sarrafo de madeira de mesmo comprimento que a tábua (Figura 4), porém de altura de cerca de $5 \mathrm{~cm}$, e nele foi colado medições semelhantes a uma trena, para permitir a fixação do imãs, que atuarão como emissores magnéticos para terem seus dados capturados pelo sensor presente no carrinho. A distância e a quantidade dos imãs é definida pelo professor (ou aluno). Essas informações devem ser passadas ao software utilizado para a correta captura dos dados e/ou plotagem dos gráficos. 


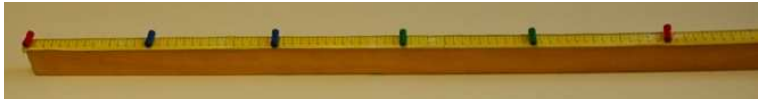

Figura 4. Sarrafo com imãs

O carrinho (Figura 5) possui uma plataforma metálica e 4 rodas. Nele foi fixado um chassi de madeira e nesse chassi estão presos um Arduino, uma mini-protoboard e um suporte para 4 pilhas. Foi utilizado um reedswitch (sensor magnético) para capturar o tempo (em segundos) em que o carrinho passa pelos imãs. Utilizou-se também de um transmissor por radiofrequência para enviar a partir do carrinho, por ondas de radiofrequência, os tempos capturados, para o computador, ao longo do deslocamento do carrinho.

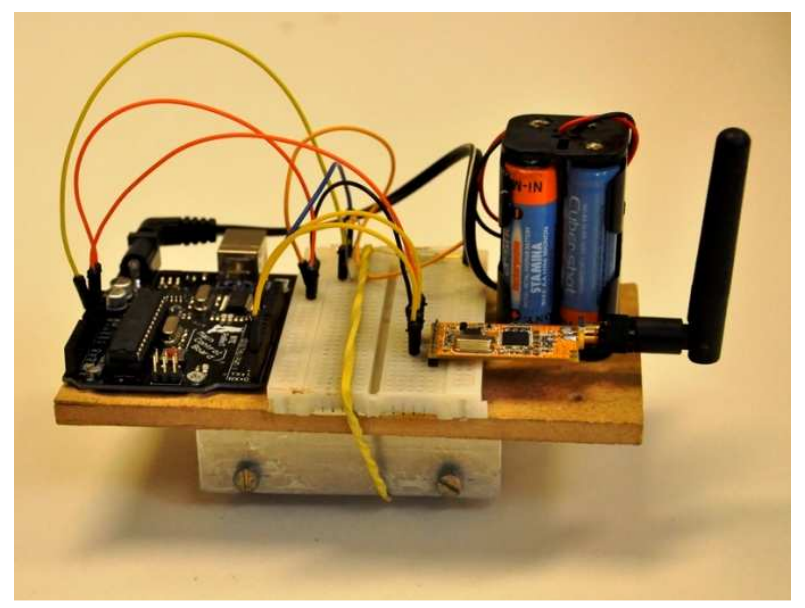

Figura 5. Detalhes do carrinho

O custo aproximado dos componentes do carrinho (placa Arduino ( $\mathrm{R} \$ 70,00$ ), módulo de comunicação Sem Fio-APC220 (R \$ 180,00), protoboard (R \$ 13,00), suporte para pilhas $(\mathrm{R} \$ 4,00)$ e readswitch $(\mathrm{R} \$ 1,00))$ é de cerca de $\mathrm{R} \$ 270,00$. O projeto pode ser barateado, substituindo o módulo de comunicação sem fio por outro semelhante, porém que utiliza a tecnologia Bluetooth. $\mathrm{O}$ valor desse dispositivo (Bluetooth) custa em torno de $\mathrm{R} \$ 40,00$. A protoboard também pode ser suprimida, a fim de redução de custos.

\section{Utilizando Robótica Livre para Aprendizagem de Movimento Retilíneo}

Atualmente existem várias formas de interagir com os robôs criados em projetos de robótica. Neste caso, onde o experimento será utilizado por alunos do Ensino Médio, não é esperado que eles interajam ou programem o robô através de comandos de linguagem de programação, por ser algo ainda desconhecido e complexo para eles. Nessas situações, existem softwares que "escondem" a complexidade da programação, apresentado aos alunos uma interface amigável onde, através de comandos de alto nível ou preenchimento de campos, ordens e parâmetros podem ser transmitidos do robô para o computador e/ou vice-versa (Arduino 2013). Assim, a fim de apresentar uma interface mais amigável aos alunos que irão utilizar o dispositivo, ao invés de utilizar o "Serial Monitor" da IDE do Arduino, cuja interface é muito simples, baseada em caracteres somente, optou-se por criar uma interface em um navegador web. Para tal, foi 
desenvolvida uma aplicação em uma interface web, desenvolvida em PHP, rodando em conjunto com um servidor Apache.

Antes do carrinho iniciar o seu deslocamento, o software oferece ao usuário a possibilidade de informar onde os sensores (imãs) estarão e que retorno ele deve apresentar (gráficos ou somente os tempos coletados), conforme figura a seguir.

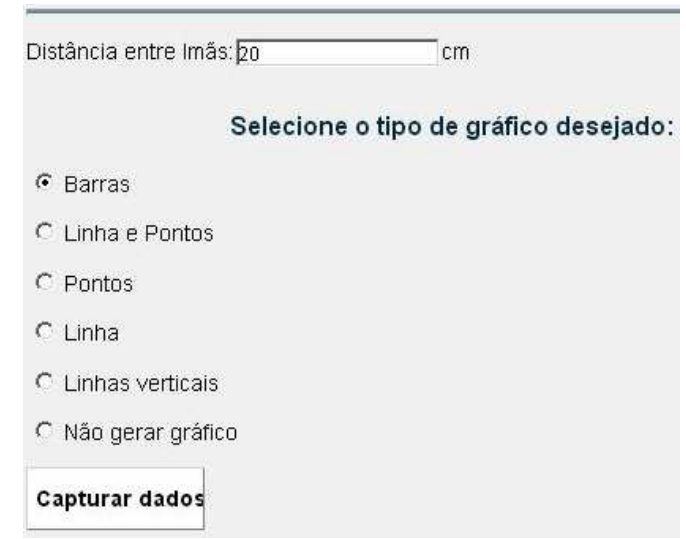

Figura 6. Tela inicial para configuração da captura de dados

O carrinho, ao passar pelo primeiro imã, inicia a contagem do tempo. Quando ele passar nos próximos imãs, os tempos serão capturados e repassados ao computador, através do dispositivo de transmissão sem fio que se encontra conectado ao Arduino. Ao terminar o deslocamento, a aplicação exibe na tela do computador, em uma página do navegador, a informação que o deslocamento encerrou e as opções de visualizações possíveis. É possível, atualmente, a exibição dos gráficos: velocidade em função do tempo e aceleração em função do tempo. Outros gráficos podem ser programados para serem gerados. Também existe a opção de informar apenas as distâncias e os tempos, a fim de que os alunos possam usá-los para atender uma atividade específica solicitada pelo professor, tal como desenhar determinado gráfico a partir desses dados "a mão livre".

Como pode ser observado, a implementação em sala de aula da presente proposta permite que professores e alunos se utilizem de um conjunto robótico para efetuar observações e estudos do movimento retilíneo de um corpo em condições controladas. Também permite a aquisição em tempo real de dados intrínsecos do movimento (posição em função do tempo) que organizados e apresentados em forma de tabelas permitem uma análise posterior através da elaboração de gráficos adequados que poderão ser efetuados "a mão" ou com o uso de outros softwares, tudo a critério do professor e/ou dos próprios estudantes. Isto por sua vez dá maior dinamismo às atividades didáticas e estimula os alunos para a observação e o estudo da disciplina de Física. Cabe ainda mencionar que os equipamentos didáticos encontrados no comércio para efetuar experiências didáticas similares a aqui apresentada possuem custo elevado, o que faz com que muitas escolas de ensino médio sejam carentes de aulas práticas. 


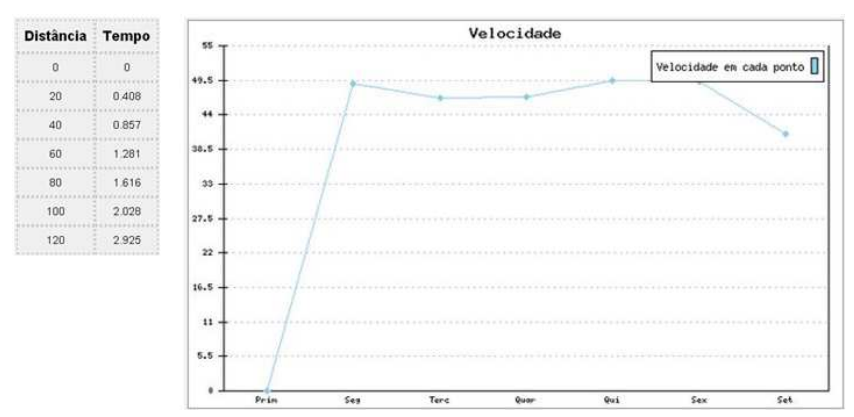

Figura 7. Exibição da dos dados capturados após o deslocamento

Uma nova versão da interface gráfica que permite a comunicação com o Arduino e exibição dos dados capturados está sendo desenvolvida em Python. As razões para essa troca de tecnologia foram devido a simplicidade na programação das necessidades do projeto, disponibilização de bibliotecas gráficas adequadas e de fácil uso e rapidez no desenvolvimento de rotinas, em relação a versão atual, implementada em PHP.

\section{Conclusões}

Com a popularização de tecnologias livre como o Arduino, a robótica começou a ficar mais acessível e aplicações de cunho educacional começaram a ser possíveis de serem realizadas. A Robótica Educacional Livre possibilita a implementação de dispositivos robóticos de baixo custo, muitas vezes por conta da utilização de materiais descartados de equipamentos eletrônicos.

Nesse artigo é descrita uma proposta didática de fácil realização para o ensino do conceito de movimento retilíneo. Entretanto, é possível apontar que dada a flexibilidade da tecnologia livre e das interfaces de software disponíveis, a robótica livre possui um grande potencial no ensino de Ciências como um todo.

Por fim, a proposta de atividades descrita no artigo demonstra claramente a aplicabilidade didática desse recurso na educação, bem como corrobora que o uso dessas tecnologias pode vir a ampliar a capacidade de ensino e o aprendizado multidisciplinar que o aluno pode vir a ter com o experimento.

\section{Referências}

Arduino. Arduino. Disponível em http://arduino.cc/. Acesso em Mar. 2013.

Arduino. User Interface. Disponível em http://playground.arduino.cc/Main/Interfacing WithHardware\#ui/. Acesso em Mar. 2013.

Barbero, A., Demo, B., Vaschetto, F. A Contribution to the Discussion on Informatics and and Robotics in Secondary Schools. Disponível em: http://www.innoc.at/fileadmin/ user_upload/_temp_/RiE/Proceedings/71.pdf. Acesso em: Mar. 2013.

César, D., Robótica Livre: Robótica Educacional com Tecnologias Livres. Disponível em http://libertas.pbh.gov.br/ danilo.cesar/robotica_livre/artigos/artigo_fisl_2005_pt _final.pdf. Acesso em: Abr. 2013. 
César, D., Bonilla, M. Robótica Pedagógica com Soluções Tecnológicas Livres no Cet CEFET em Itabirito - Minas Gerais - Brasil. In: Anais do XXVII Congresso da SBC, 2007. Disponível em: http://br-ie.org/pub/index.php/wie/article/download/953/939. Acesso em Abr. 2013.

Lieberknecht, E. Robótica Educacional. Disponível em http://www.portalrobotica. com.br/site/index.php?option=com_content\&view=article\&id=4\&Itemid=2 Acesso em Abr. 2013.

Malec, J. Some thoughts on robotics for education. Proceedings of the American Association for Artificial Intelligence Symposium on Robotics and Education. Disponível em http://fileadmin.cs.lth.se/cs/Personal/Jacek_Malec/psfiles/ aaai01rae.pdf. Acesso em Maio de 2013. Acesso em Abr. 2013.

NASA. Nasa Robotics - Robotics Alliance Project. Disponível em http://robotics. nasa.gov. Acesso em abr. 2013.

OBR. Olimpíada Brasileira de Robótica. Disponível em http://obr.org.br/ Acesso em Mar. 2013.

Santos, F., Nascimento, F., Bezerra, R. REDUC: A Robótica Educacional como Abordagem de Baixo Custo para o Ensino de Computação em Cursos Técnicos e Tecnológicos. In: Anais do XXX Congresso da SBC, 2007. Disponível em: http://www.br-ie.org/WIE2010/pdf/st06_02.pdf Acesso em Fev. 2013.

Sergeyev, A., Alaraje, N. Promoting Robotics Education: Curriculum and State-of-theArt Robotics Laboratory evelopment, the Technology Interface Journal, Spring, 2010, Vol.10 N.3. 